This is the peer reviewed version of the following article:

Cha, S., Marekha, B. A., Wagner, M., \& Hunger, J. (2019). Hydrogen-bond structure and dynamics of TADDOL asymmetric organo-catalysts correlate with catalytic activity. Chemistry - A European Journal, 25(42), 9984-9990. doi:10.1002/chem.201901594.

, which has been published in final form at: $\underline{10.1002 / \text { chem.201901594 }}$

\title{
Hydrogen-bond structure and dynamics of TADDOL asymmetric organo-catalysts correlate with catalytic activity
}

Seoncheol Cha, Bogdan Marekha, Manfred Wagner, and Johannes Hunger*

This article may be used for non-commercial purposes in accordance with publisher's Terms and Conditions for Use of Self-Archived Versions 


\title{
Hydrogen bond structure and dynamics of TADDOL asymmetric organo- catalysts correlate with catalytic activity
}

\author{
Seoncheol Cha, ${ }^{[\mathrm{a}]}$ Bogdan Marekha, ${ }^{[\mathrm{a}]}$ Manfred Wagner, ${ }^{[\mathrm{a}]}$ Johannes Hunger ${ }^{*}[\mathrm{a}]$ \\ ${ }^{[a]}$ Max Planck Institute for Polymer Research, Ackermannweg 10, 55128 Mainz, Germany \\ *email: hunger@mpip-mainz.mpg.de
}

\begin{abstract}
The catalytic efficiency of diol-based organo-catalysts has been shown to strongly depend on the diols molecular structure including hydrogen-bonding, yet, the underlying molecular-level origins have remained elusive. Here we study inter- and intramolecular hydrogen-bonding of two isomeric diolbased catalysts (TADDOLs) in solution: 1-naphthyl substituted TADDOL (1nTADDOL), which exhibits high catalytic efficiency, and 2-naphthyl substituted TADDOL (2nTADDOL), which is a poor catalyst. Using nuclear magnetic resonance and infrared spectroscopy, we find comparable hydrogenbond strengths for both TADDOLs in solution, however, significantly slower bonding dynamics for $1 \mathrm{nTADDOL}$. In aromatic solvents, we find 1nTADDOL to form less, but longer-lived, intermolecular $\mathrm{OH} \cdots \pi$ bonds to solvent molecules, as compared to 2 nTADDOL. Thus, rather than previously suggested differences in intermolecular hydrogen-bonding strengths, our results suggest that the hydrogen-bonding kinetics and entropies differ for both TADDOLs, which also explains their vastly different catalytic activities.
\end{abstract}




\section{Introduction}

In recent years, asymmetric organo-catalysis has proven to be a promising alternative for transition metal based asymmetric catalysis. ${ }^{[1-5]}$ The main advantage of organo-catalysts is - instead of containing potentially toxic transition metals as in conventional asymmetric catalysis - that they solely consist of organo-chemical motifs with hydrogen-bonding functional groups being the most abundant and common active site motifs. While the chiral framework of the catalysts provides the asymmetric environment, the active sites bind and activate the substrate molecules and, as such, are crucial for the catalytic activity.

Among asymmetric organo-catalysts, diol-based molecules are arguably one of the most studied catalysts. $^{[1,4,5]}$ The catalyst $\alpha, \alpha, \alpha^{\prime}, \alpha^{\prime}$-tetraaryl-1,3-dioxolane-4,5-dimethanol (TADDOL), which is available at large scales at affordable costs, has been proven to provide excellent stereoselectivity for a wide range of chemical conversions, including, e.g., the hetero-Diels-Alder and hetero-Mukaiyamaaldol reactions. ${ }^{[6-11]}$ Based on quantum chemical calculations, mechanistic studies, and X-ray crystallography, ${ }^{[5,8,9,12-15]}$ the fundamentals of the catalyst-substrate interaction and the reaction mechanisms have been explored. These studies have suggested that the hydroxyl $(\mathrm{OH})$ groups form an intramolecular hydrogen-bond, but TADDOL's catalytic activity stems from intermolecular hydrogenbonding between a hydroxyl group of TADDOL and carbonyl groups $(\mathrm{C}=\mathrm{O})$ of a ketone or aldehyde of the substrate molecules. ${ }^{[5,8,9,12-15]}$ Despite these pioneering studies having provided atomistic insight into the hydrogen-bonded structure of the catalysts, such quantum chemical studies performed for a single molecule in the gas-phase or in polarized continuum model as well as x-ray studies performed for solid-state samples could not take into account solvent or finite temperature effects - highly relevant to catalysis. It is particularly challenging to explore, in gas-phase computations or solid state studies, the effects of thermally induced fluctuations of the catalyst and competitive binding to the solvent. ${ }^{[9,12]}$

(a)<smiles>CC1(C)OC(C([Al])([Al])[Al])C(C(O)(Br)Br)O1</smiles>

(d) (b)

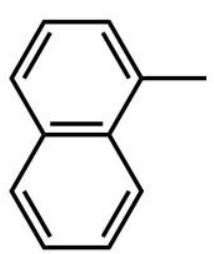

Ar $=1$-naphthyl (c)

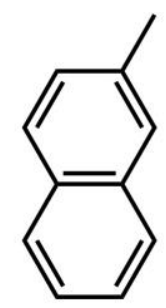

$\mathrm{Ar}=2$-naphthyl

(e)
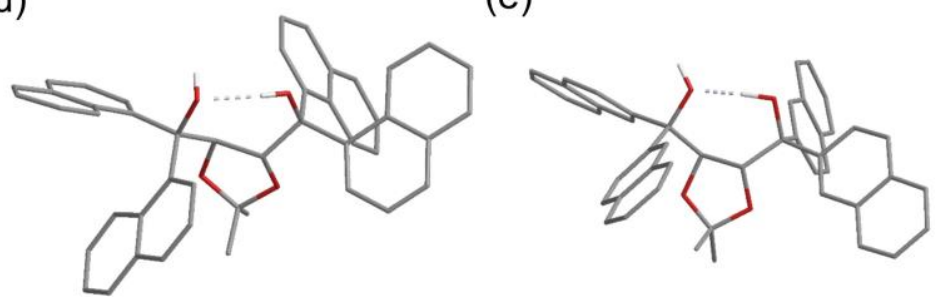

Figure 1. (a) molecular structure of TADDOL with either (b) 1-naphthyl- or (c) 2-naphthylsubstituents as Aryl group and three-dimensional models of (d) 1nTADDOL and (e) 2nTADDOL based on crystal structures of TADDOLs. ${ }^{[16]}$ For visual clarity only hydrogen atoms of OH groups are shown in the models.

To study the effect of hydrogen-bonding characteristics on TADDOL catalysis, two common TADDOL catalysts with different substituents are a popular guinea pig: 1-naphthyl substituted TADDOL (1nTADDOL) and 2-naphthyl substituted TADDOL (2nTADDOL). Despite these two catalysts differing only by the isomerism of the naphthyl substituent (see Fig. 1), their catalytic activity is profoundly different: For the Diels-Alder reaction of an aminosiloxydiene and methacrolein 
2nTADDOL provides less than $50 \%$ yield and enantiomeric excess (ee), while the presence of 1 nTADDOL as catalyst gave more than $80 \%$ yield and $90 \% e e .{ }^{[7]}$ Similar superior performance of $1 \mathrm{nTADDOL}$ as compared to 2 nTADDOL has also been reported for various substrates and products. ${ }^{[5,8,11]}$ These different catalytic activities have been investigated using crystallography, which have indicated that the dynamics of the naphthyl groups of both TADDOLs differ. In 2nTADDOL both naphthyl groups rotate rather freely in contrast to $1 \mathrm{nTADDOL}$ where the rotation of the side groups is hindered ${ }^{[7,16]}$ While the differences in $e e$ could possibly be rationalized by these different dynamics, the markedly different catalytic yields suggest that also the activation of the substrates (e.g. the acidity of the $\mathrm{OH}$ group) by both TADDOLs markedly differ. ${ }^{[7]}$ The activation of the substrate in turn is intimately related to the hydrogen-bond characteristics of TADDOL, e.g. the hydrogen-bond donor strength. The hydrogen-bonding characteristics of both TADDOLs have however remained elusive under relevant reaction conditions.

Here, we explore the effect of the different naphthyl substituents of TADDOL on their hydrogenbonding in solution using a combination of infrared (IR) and nuclear magnetic resonance (NMR) spectroscopy. We use both the $\mathrm{OH}$ stretching vibration in the IR spectrum and the ${ }^{1} \mathrm{H}$ chemical shifts of the protons of the $\mathrm{OH}$ groups in NMR spectrum to elucidate hydrogen-bonding in both TADDOLs. Using the combination of vibrational motions occurring on fast timescales and the NMR chemical shifts, which are sensitive to slower hydrogen-bonding dynamics, we find that 1nTADDOL and 2nTADDOL differ by their structural rigidity. The rigidity results in both different intra- and different intermolecular hydrogen-bonding, with the latter being also relevant to understanding the different catalytic activity.

\section{Results and Discussion}

\section{NMR spectroscopy of 1nTADDOL and 2nTADDOL}

To explore the hydrogen-bonding of the two differently substituted TADDOL catalysts in solution, we compare their solution ${ }^{1} \mathrm{H}$ NMR spectra in toluene- $\mathrm{d}_{8}$, as toluene is a solvent commonly used in TADDOL catalysis. ${ }^{[7,8,11]}$ Even without any detailed peak assignment, we observe marked differences in the NMR spectra of both TADDOLs: In line with previous reports, the proton peaks of 1nTADDOL (Fig. 2a) are spectrally broad, which can be attributed to the structural rigidity of 1 nTADDOL, i.e. the restricted rotation of 1-naphthyl groups of 1nTADDOL (Fig. 1d). ${ }^{[16,17]}$ Conversely, we find the peaks of 2nTADDOL to be motionally narrowed (Fig. 2b) consistent with a rather free rotation of the 2naphthyl group. ${ }^{[16,17]}$ These narrow peaks can be ascribed to the protons of the naphthyl groups at 7 $9 \mathrm{ppm}$, the $\mathrm{CH}$ groups at $5.3 \mathrm{ppm}$, the hydroxyl groups at $4.8 \mathrm{ppm}$ and the $\mathrm{CH}_{3}$ groups at $1.1 \mathrm{ppm}$. Consistent with this assignment, we find the integrals of these ranges to have an approximate 28:2:2:6 ratio. Due to the broadened peaks in the spectra of $1 \mathrm{nTADDOL}$, peak assignment is less straightforward, however, the assigned chemical shift ranges are almost certainly very similar and have been studied in more detail by others. ${ }^{[16,17]}$ 


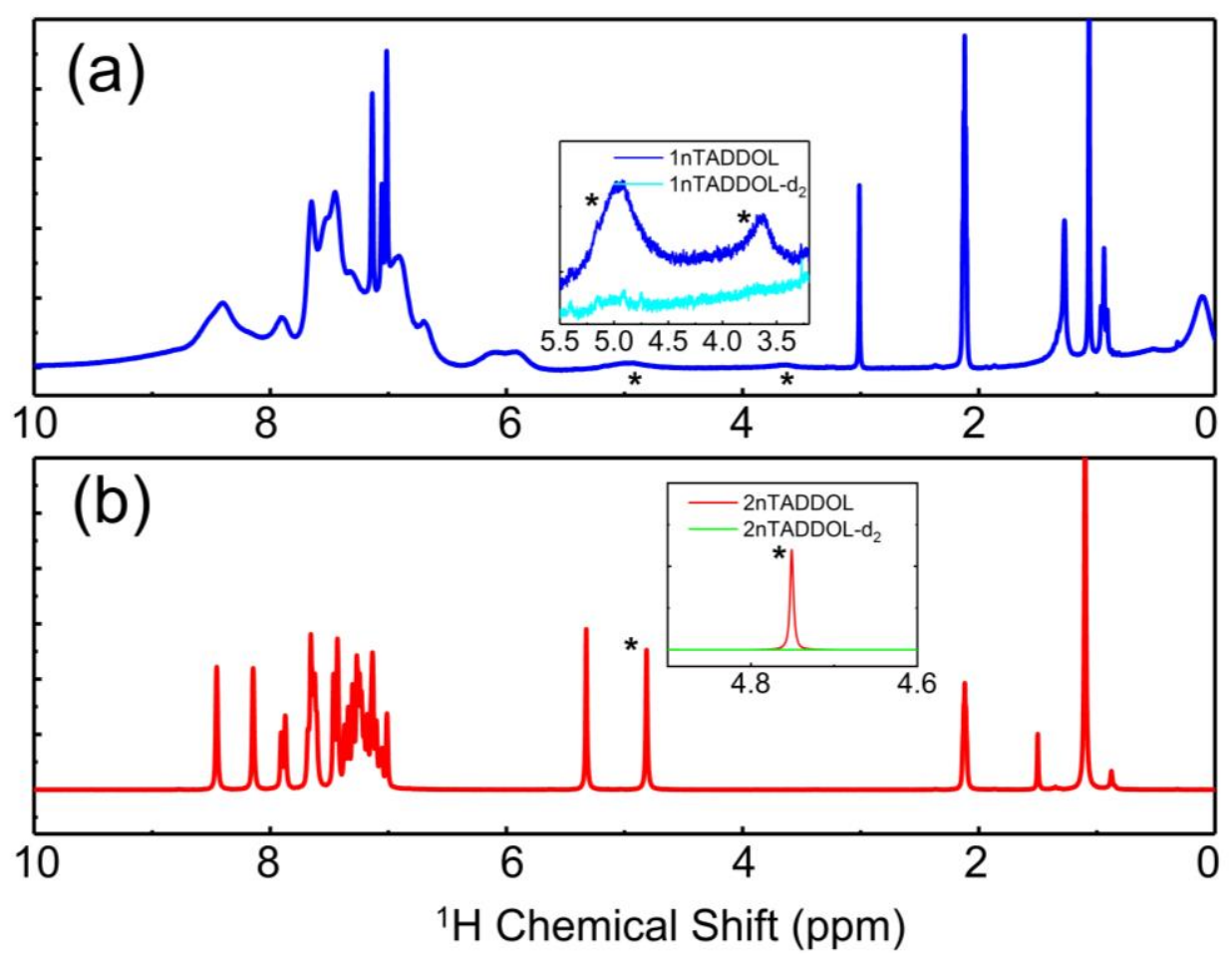

Figure 2. ${ }^{1} \mathrm{H}$ NMR spectra of $\sim 30 \mathrm{mM}$ (a) $1 \mathrm{nTADDOL}$, and (b) 2nTADDOL dissolved in toluene- $\mathrm{d}_{8}$ at $298 \mathrm{~K}$. The peaks at 2.1, 7.0 and $7.1 \mathrm{ppm}$ are due to residual protons of toluene. The insets show the comparison of (a) $1 \mathrm{nTADDOL}$ and $1 \mathrm{nTADDOL}-\mathrm{d}_{2}$ and (b) $2 \mathrm{nTADDOL}$ and $2 \mathrm{nTADDOL}-\mathrm{d}_{2}$ for the $\mathrm{OH}$ proton signals *

To obtain information on the hydrogen-bonding characteristics of both TADDOL catalysts we investigate the chemical shift of the hydroxyl protons of TADDOL in the NMR spectra in more detail. The chemical shift of $\mathrm{OH}$ protons is a particularly sensitive reporter for the bonding state, ${ }^{[18-20]}$ and allows assessing the intramolecular hydrogen-bond strength of diols. ${ }^{[1,22]}$ For 2nTADDOL the $\mathrm{OH}$ protons lead to a single peak at $\sim 4.8 \mathrm{ppm}$, consistent with the disappearance of this NMR signal upon exchanging this proton for deuterium by adding $\mathrm{D}_{2} \mathrm{O}$ (see inset of Fig. $2 b$ ). The presence of a single, motionally-averaged peak shows that the two $\mathrm{OH}$ protons of the two hydroxyl groups exchange sufficiently fast so that they cannot be discriminated using NMR. To locate the $\mathrm{OH}$ protons in the broadened spectra of $1 \mathrm{nTADDOL}$, we also isotopically substitute the $\mathrm{OH}$ protons by deuterium. As can be seen from the comparison of the ${ }^{1} \mathrm{H}$ NMR spectrum of isotopically substituted 1 nTADDOL- $\mathrm{d}_{2}$ to the spectrum of the unsubstituted 1nTADDOL in the inset of Fig. 2a, two broad peaks at $\sim 5$ ppm and $~ 3.6$ ppm disappear upon isotopic substitution. Thus, we assign these peaks to the two $\mathrm{OH}$ groups of 1nTADDOL (for discussion of the peak intensities, see below). The chemical shift of the down-field shifted peak at $\sim 5$ ppm indicates that this proton is hydrogen-bonded ${ }^{[7,8,16]}$ and thus represents the $\mathrm{OH}$ group, which donates the intramolecular hydrogen-bonded ("bound $\mathrm{OH}^{\prime}$ ) to TADDOL's second $\mathrm{OH}$ group. The chemical shift of the proton of the second $\mathrm{OH}$ group, which accepts the intramolecular hydrogen-bond, is accordingly up-field shifted at $\sim 3.6 \mathrm{ppm}$, relative to the bound $\mathrm{OH} \cdot \cdot^{[7,8,16]}$ Interestingly, the observation of two disparate peaks for the two OH groups of 1nTADDOL suggests that also the hydrogen-bonded structure of $1 \mathrm{nTADDOL}$ is rather rigid and the intramolecular hydrogenbond does not exchange on the relatively slow NMR timescale of $\sim 2 \mathrm{~ms}$ (estimated assuming a $1.4 \mathrm{ppm}$ peak separation on the $850 \mathrm{MHz}$ NMR spectrometer used for these experiments). 


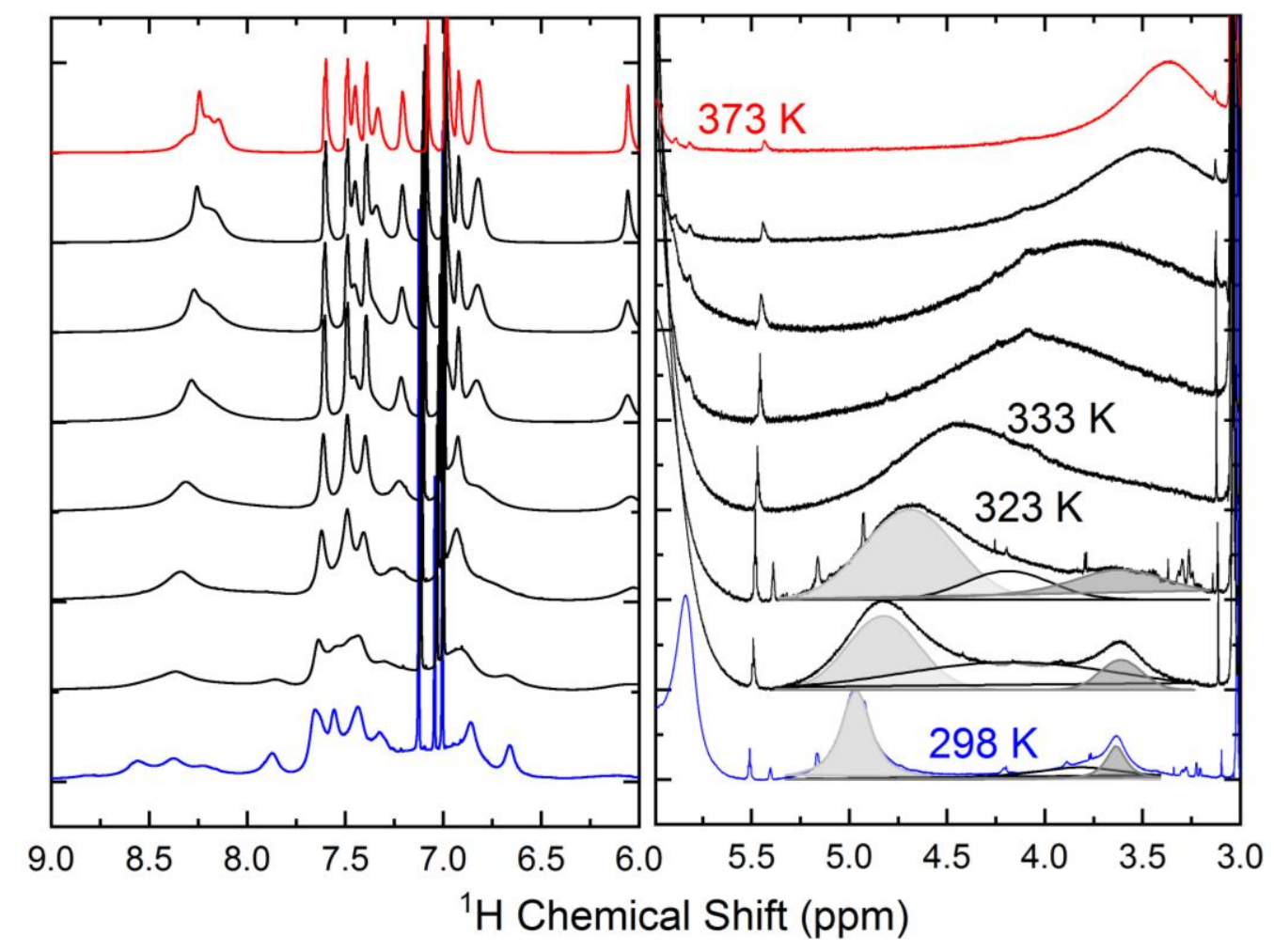

Figure 3. Temperature dependent ${ }^{1} \mathrm{H}$ NMR spectra of $\sim 30 \mathrm{mM}$ 1nTADDOL dissolved in toluene- $\mathrm{d}_{8}$. Blue solid line corresponds to experiments at $298 \mathrm{~K}$. Temperature is increased by $10 \mathrm{~K}$ increments

from $313 \mathrm{~K}$ up to $373 \mathrm{~K}$ (red solid line). NMR spectra in the right panel (6 to $3 \mathrm{ppm}$ range) are normalized to the highest amplitude of the $\mathrm{OH}$ proton signal. Gray solid lines filled with light grey, white, and gray areas shows the decomposition of the (3 to 5.5ppm) signals into three components.

To further explore the rigidity and exchange dynamics of the intramolecular hydrogen-bond of 1nTADDOL, we perform temperature dependent NMR experiments on 1nTADDOL dissolved in toluene- $\mathrm{d}_{8}$ (Fig. 3). As can be seen from these experiments, the peaks of the naphthyl groups at 7 to $8.5 \mathrm{ppm}$ are significantly broadened at ambient temperature $(298 \mathrm{~K})$ and become narrower at elevated temperatures, which is in line with the restricted, thermally activated rotation of naphthyl groups leading to the spectral broadening. The split $\mathrm{OH}$ peaks at $5 \mathrm{ppm}$ and $3.6 \mathrm{ppm}$ coalesce to a single peak at a temperature of $\sim 333 \mathrm{~K}$. This coalescence indicates that at this temperature the exchange rate becomes faster than half of the frequency difference of the two exchanging peaks. ${ }^{[23,24]}$ Thus, only at temperatures as high as $\sim 333 \mathrm{~K}$ the exchange rate of the intramolecular hydrogen-bond becomes comparable to the NMR time scale of our experiments of $\sim 2 \mathrm{~ms}$. At even higher temperatures the coalesced peak shows a continuous up-field shift with increasing temperature, which can be ascribed to a thermally induced weakening of the average hydrogen-bond strength of both $\mathrm{OH}$ groups.

Though the presence and coalescence of two disparate peaks is consistent with thermally induced hydrogen-bond exchange of the intramolecular hydrogen bond, already visual inspection of the peak areas of the two $\mathrm{OH}$ signals at $\sim 5 \mathrm{ppm}$ and $\sim 3.6 \mathrm{ppm}$ appears inconsistent with this notion at a first glance. The peak intensities of these two signals seem to significantly deviate from a 1:1 ratio, which would be expected based on the two $\mathrm{OH}$ protons of TADDOL. Contributions from residual water and the presence of intermolecular (rather than intra-molecular) hydrogen bonds due to aggregation of TADDOLs in solution can be excluded, owing to the low water concentration, and TADDOL's concentration-independent diffusion coefficient (see Supporting Information, SI, Fig. S1 and Tab. S1), 
respectively. Thus, the unbalanced peak integrals of the two hydroxyl protons must have a different molecular level origin, which will be discussed in the following.

\section{IR spectroscopy of 1n- and 2n-TADDOL}
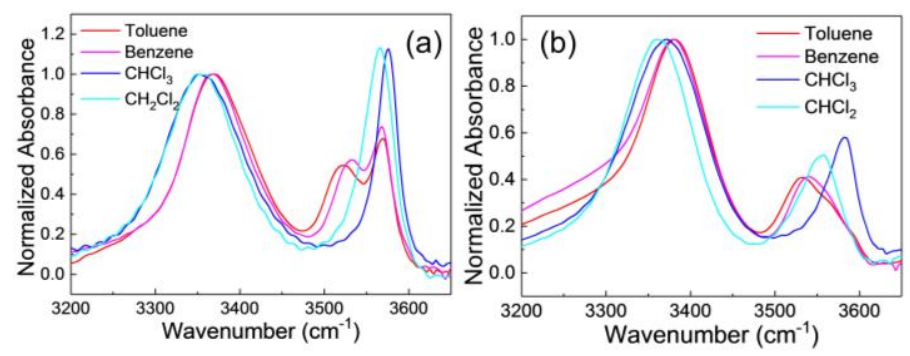

(c)

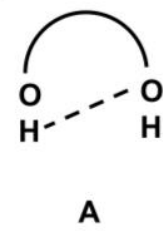

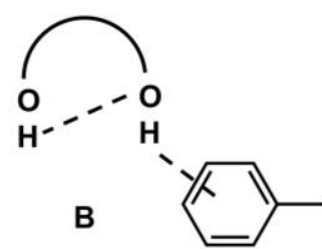

Figure 4. IR spectra of $\sim 100 \mathrm{mM}$ (a) 1nTADDOL and (b) 2nTADDOL in different solvents. The absorption due to the solvent was subtracted and spectra were normalized to the maximum absorbance at $3300-3400 \mathrm{~cm}^{-1}$. (c) Scheme of the intramolecular hydrogen-bond (A) and the intermolecular hydrogen-bond to aromatic solvents like e.g. toluene (B).

To further elucidate the peculiar intensities of the $\mathrm{OH}$ proton peaks of $1 \mathrm{nTADDOL}$ in NMR, we record IR spectra of TADDOLs in solution. In contrast to NMR (using frequencies of hundreds of MHz), IR spectroscopy (at frequencies of tens to hundreds of $\mathrm{THz}$ ) probes the bonding state on shorter timescales. As such, IR experiments can also discriminate different bonding states for 2nTADDOL, where NMR spectra show only a single, motionally-averaged peak. In the following, we focus on the $\mathrm{OH}$ stretching vibrations at $3200-3600 \mathrm{~cm}^{-1}$, which are sensitive to inter- and intramolecular interactions ${ }^{[18,22,25-29]}$ For similar diols that form an intramolecular hydrogen-bond, a broad lower frequency $\mathrm{OH}$ stretching band, which is red-shifted due to the intermolecular hydrogen-bond ("bound $\mathrm{OH}$ "), and a blue-shifted $\mathrm{OH}$ stretching mode, with the $\mathrm{OH}$ group exposed to the solvent ("free $\mathrm{OH}^{\text {") }}$ could be discriminated. ${ }^{[30]}$

In Fig. 4 we show the IR spectra for 1nTADDOL (Fig. 4a) and 2nTADDOL (Fig. 4b) at frequencies characteristic to the $\mathrm{OH}$ stretching modes in different solvents. From the spectra recorded in toluene (red lines in Fig. 4) we find a broad band centred at $\sim 3370 \mathrm{~cm}^{-1}$ for $1 \mathrm{nTADDOL}$ and at $\sim 3380 \mathrm{~cm}^{-1}$ for 2nTADDOL. These bands, $v \mathrm{OH}_{\text {intra }}$, are typical for hydrogen-bond donating $\mathrm{OH}$ groups (bound $\mathrm{OH}$ or sometimes referred to $\delta$-OH groups $)^{[30]}$ and thus provide evidence for intramolecular hydrogen-bonding between $\mathrm{OH}$ groups within TADDOL. We note, that adjacent to the band at $\sim 3370 \mathrm{~cm}^{-1}$ the spectra exhibit a weak shoulder at $\sim 3250 \mathrm{~cm}^{-1}$, which will be discussed in more detail below. The slight redshifted maximum in the $\mathrm{vOH}_{\text {intra }}$ band for $1 \mathrm{nTADDOL}$ compared to 2nTADDOL points towards a slightly stronger intramolecular bond in $1 \mathrm{nTADDOL}$ relative to 2 nTADDOL.

At higher frequencies we observe distinct blue-shifted vibrational bands at $3500-3600 \mathrm{~cm}^{-1}$, which we ascribe to the $\mathrm{OH}$ group that accepts the intramolecular hydrogen-bond. Interestingly, the blue-shifted absorption features exhibit a double peak structure for both TADDOLs dissolved in toluene or benzene (Fig. 4). This double peak structure of the blue-shifted bands is absent when both TADDOLs are dissolved in chloroform or dichloromethane, despite the polarities being rather similar, as judged from the static dielectric constants:, $\varepsilon$. benzene: $\varepsilon=2.28$; toluene: $\varepsilon=2.38 ; \mathrm{CHCl}_{3}: \varepsilon=4.81, \mathrm{CH}_{2} \mathrm{Cl}_{2}: \varepsilon=$ 8.93 at $293 \mathrm{~K}$ to $298 \mathrm{~K} .{ }^{[31]}$ We note that in hydrogen-bond accepting solvents like tetrahydrofuran (THF) or acetone the blue-shifted bands are completely absent (see Fig. S2, SI), similar to what was found for diols interacting with dimethyl sulfoxide. ${ }^{[32]}$ In tetrahydrofuran or acetone the bound $\mathrm{OH}$ bands are centered at even lower wavenumbers than the bound $\mathrm{OH}$ band in toluene, which indicates that the 
intermolecular interaction between TADDOLs OHs and the solvent is stronger than intramolecular hydrogen-bonding. Indeed, the center frequency of the intermolecular bound $\mathrm{OH}$ group correlates with the hydrogen-bond acceptor number of the solvent (Fig. S3, SI). ${ }^{[32,33]}$ Thus, we conclude from these experiments that the high frequency $\mathrm{OH}$ bands markedly depend on the solvent and for aromatic solvents intermolecular interaction with the solvent can be readily resolved.

The double peak structure of the blue-shifted spectral features above $3500 \mathrm{~cm}^{-1}$ is exclusively observed for aromatic solvents (toluene and benzene). In line with previous studies on interaction between alcohols and aromatic solvents ${ }^{[34,35]}$ the double peak structure can be explained by the simultaneous presence of (i) free $\mathrm{OH}$ groups that are neither inter- nor intramolecular hydrogen bond donors and hence lead to the high frequency peak $\mathrm{vOH}_{\text {Free }}$ at $\sim 3570 \mathrm{~cm}^{-1}$ and (ii) $\mathrm{OH}$ groups that interact with the aromatic $\pi$ electrons of the solvent leading to the $v \mathrm{OH}_{\pi}$ band at $\sim 3530 \mathrm{~cm}^{-1}$. We note that the simultaneous presence of these two $\mathrm{OH}$ groups can also explain the peculiar ratio of the peak intensities of both $\mathrm{OH}$ protons in the NMR spectra: The proton peak observed at $\sim 3.6 \mathrm{ppm}$ in the NMR spectra can be well-described with two distinct peaks (see right panel of Fig. 3). The sum of the integrals of the two Voigt peaks giving rise to the broad peak at $3.6 \mathrm{ppm}$ equals the integral of the peak at $\sim 5 \mathrm{ppm}$, consistent with the 1:1 ratio of the integrals, which is expected for the two OH protons of 1nTADDOL (for details see SI, Figs. S4 \& S5). Hence, our results indicate that for 1nTADDOL in toluene the dissociation kinetics of the $\mathrm{OH} \cdots \pi$ bonds to form a free-OH group is sufficiently slow so that both $\mathrm{OH}$ groups can be discriminated in the NMR spectra.

To obtain more insight into the differences between the "good catalyst" 1nTADDOL and the "bad catalyst" 2nTADDOL, we focus on the center frequencies of the vibrational bands in toluene of both TADDOLs. The center frequencies are obtained by modelling the spectra with a combination of four Voigt bands for the intramolecularly bonded $\mathrm{OH}$ group, the $\mathrm{OH} \cdots \pi$ bonded $\mathrm{OH}$ group, the free $\mathrm{OH}$ group, and the low-frequency shoulder at $\sim 3250 \mathrm{~cm}^{-1}$ (for details see SI, Fig. S6). We note that the band to account for the red-shifted shoulder at $\sim 3250 \mathrm{~cm}^{-1}$ is spectrally broad. As such it is challenging to determine its exact center frequency and we refrain from more detailed interpretation of the band position. For the three narrower absorption peaks the thus obtained center frequencies for 1nTADDOL $\left(v \mathrm{OH}_{\text {intra }}: 3370 \mathrm{~cm}^{-1}, v \mathrm{OH}_{\pi}: 3525 \mathrm{~cm}^{-1}\right.$, and $\left.v \mathrm{OH}_{\text {Free }}: 3570 \mathrm{~cm}^{-1}\right)$ and for $2 \mathrm{nTADDOL}\left(\mathrm{vOH}_{\text {intra }}\right.$ : $3380 \mathrm{~cm}^{-1}, \nu \mathrm{OH}_{\pi}: 3530 \mathrm{~cm}^{-1}$, and $\nu \mathrm{OH}_{\text {Free: }}: 3570 \mathrm{~cm}^{-1}$ ) are rather similar. This similarity indicates that the hydrogen-bond strengths for both TADDOLs are comparable. Conversely, the ratio of the peak amplitudes of $\mathrm{vOH}_{\text {Free }}$ and $\mathrm{vOH}_{\pi}$ markedly differ: While for $1 \mathrm{nTADDOL}$ the maximum absorbance at $3520 \mathrm{~cm}^{-1}$ - characteristic to $v \mathrm{OH}_{\pi}$ - is lower than the peak height at $3570 \mathrm{~cm}^{-1}$ (typical for $v \mathrm{OH}_{\text {Free}}$ ), we observe the opposite ratio for 2nTADDOL. This opposing trend suggests that 2nTADDOL forms more $\mathrm{OH} \cdots \pi$ bonds with toluene than 1nTADDOL.
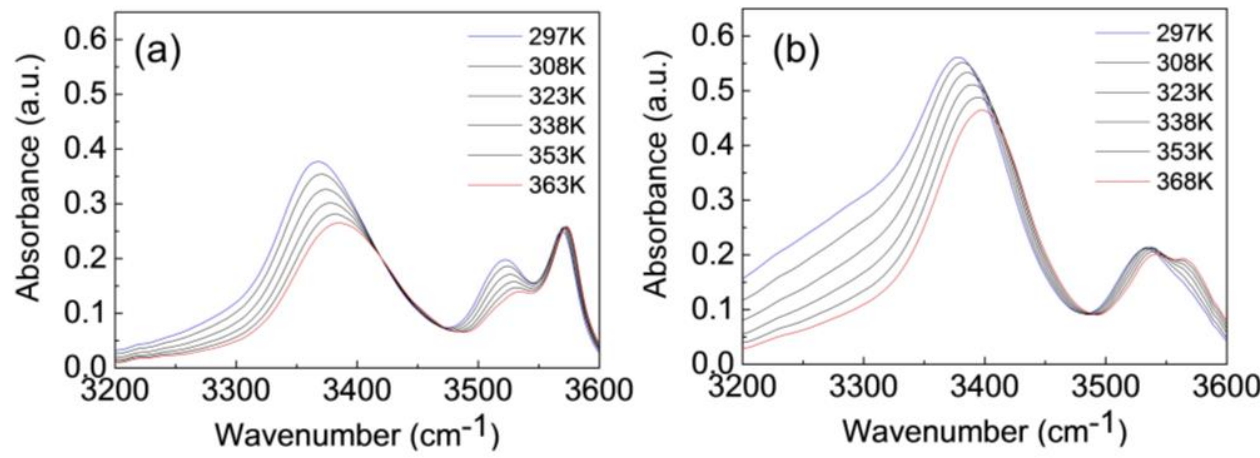

Figure 5. Background-subtracted IR spectra of $\sim 150 \mathrm{mM}$ (a) 1nTADDOL and (b) 2nTADDOL dissolved in toluene as a function of temperature. 
To study the different bonding motifs and their equilibria for both TADDOLs in toluene in more detail, we perform temperature dependent IR experiments. The maximum in the absorption of the intramolecularly bonded $\mathrm{OH}$ groups of both $1 \mathrm{nTADDOL}$ and $2 \mathrm{nTADDOL}\left(\mathrm{vOH}_{\text {intra }}\right)$ undergoes a slight blue-shift by $\sim 15 \mathrm{~cm}^{-1}$ upon increasing the temperature from $297 \mathrm{~K}$ to $\sim 360 \mathrm{~K}$ (Fig. 5 and Fig. S7, SI). This blue-shift indicates an weakening of the average intramolecular hydrogen-bond $\operatorname{strength}^{[36]}$ and can in part explain the reduction of the absorbance, as a weakening of the hydrogen-bond goes along with a reduction of the absorption cross-section. ${ }^{[37]}$ The most apparent difference between $1 \mathrm{nTADDOL}$ and 2nTADDOL at frequencies characteristic for hydrogen-bonded $\mathrm{OH}$ groups is the increase in the red-shifted shoulder at $\sim 3250 \mathrm{~cm}^{-1}$. For both TADDOLs the amplitude of the shoulder decreases with increasing temperature, though less pronounced for $1 \mathrm{nTADDOL}$ as compared to 2nTADDOL. Since

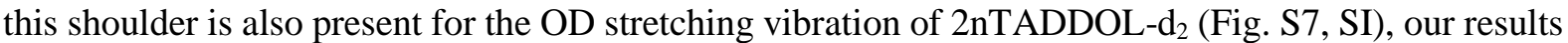
show that the low frequency shoulder stems from strongly hydrogen-bonded OH/OD groups. We find the magnitude of the shoulder to be correlated with the ratio between the peak amplitudes of the $\mathrm{vOH}_{\pi}$ and of the $\mathrm{vOH}_{\text {Free }}$ modes (see Tab. S2, SI). Thus, the results suggest that the shoulder originates from stronger intramolecular hydrogen bonds, where the other $\mathrm{OH}$ group forms an $\mathrm{OH} \cdots \pi$ bond (Fig. 4c, B); for TADDOLs with the hydrogen-bond accepting $\mathrm{OH}$ group being free, the intramolecular hydrogenbond is apparently weaker (Fig. 4c, A).

We find the two vibrational bands $\left(\mathrm{vOH}_{\text {Free }}\right.$ and $\left.\mathrm{vOH}_{\pi}\right)$ at $3500-3600 \mathrm{~cm}^{-1}$ to be well separated at all temperatures for $1 \mathrm{nTADDOL}$. The center frequency of $\mathrm{vOH}_{\text {Free }}$ does not change significantly with temperature, whereas $\mathrm{vOH}_{\pi}$ undergoes a $\sim 15 \mathrm{~cm}^{-1}$ blue-shift upon increasing the temperature to $363 \mathrm{~K}$ (Fig. 5a). Assuming that only dissociation of $\mathrm{OH} \cdots \pi$ bonds into free $\mathrm{OH}$ groups underlies the spectral changes at 3500-3600 $\mathrm{cm}^{-1 a}$ and further assuming the transition dipoles of both $v \mathrm{OH}_{\text {Free }}$ and $v \mathrm{OH}_{\pi}$ to be equal and independent of temperature, we can estimate the dissociation enthalpy of the $\mathrm{OH} \cdots \pi$ bonds to $\Delta H=\sim 2 \mathrm{kcal} / \mathrm{mol}$ from a van't Hoff plot (see SI for details, Fig. S8). This dissociation energy is broadly consistent with the $\sim 45 \mathrm{~cm}^{-1}$ red-shift of the $\mathrm{vOH}_{\pi}$ bands relative to $v \mathrm{OH}_{\text {Free }}$, which has been correlated to bonding enthalpy ranging from $-0.6 \mathrm{kcal} / \mathrm{mol}$ to $-2.45 \mathrm{kcal} / \mathrm{mol}$ for aromatic solventalcohol complexes or an interaction energy of $\sim-0.5 \mathrm{kcal} / \mathrm{mol}$ for hydrogen-bonding of water. ${ }^{[3,38,39]}$ For 2nTADDOL the $\mathrm{vOH}_{\text {Free }}$ and $\mathrm{\nu OH}_{\pi}$ bands are less well separated, which points to faster formation and dissociation kinetics of the $\mathrm{OH} \cdots \pi$ bonds, ${ }^{[40,41]}$ consistent with the NMR results above. Similar to our findings for 1nTADDOL, the red-edge and center of the $\sim 3530 \mathrm{~cm}^{-1}$ band decrease with increasing temperature and the blue-edge of the $\sim 3530 \mathrm{~cm}^{-1}$ absorbance increases with increasing temperature for $2 \mathrm{nTADDOL}$. This behavior is similar to what we find for $1 \mathrm{nTADDOL}$ and suggests that $\mathrm{OH} \cdots \pi$ bonds are thermally dissociated with increasing temperature. The observed changes in absorption with temperature are however less pronounced, which shows that $\mathrm{OH} \cdots \pi$ interactions are less susceptible to temperature for 2nTADDOL compared to 1nTADDOL. Nevertheless, the dissociation enthalpy of the $\mathrm{OH} \cdots \pi$ bond for $2 \mathrm{nTADDOL}$ as obtained from a van't Hoff plot is $\operatorname{similar}(\Delta H=\sim 3 \mathrm{kcal} / \mathrm{mol}$, Fig. S8, SI) to the enthalpy found for $1 \mathrm{nTADDOL}$. The similarity of the intermolecular interaction strengths is confirmed by ab initio calculations, which yield nearly identical intermolecular binding energies of $3.6 \mathrm{kcal} / \mathrm{mol}$ for both TADDOLs with toluene (see SI for details, Fig. S9). The similar red-shifts of $v \mathrm{OH}_{\pi} \mathrm{vs} \mathrm{OH}_{\text {Free }}$ for both TADDOLs also support the similar dissociation enthalpies for $\mathrm{OH} \cdots \pi$ bonds.

The most apparent difference between both TADDOLs in the $3500-3600 \mathrm{~cm}^{-1}$ spectral range are the relative populations of the $\mathrm{vOH}_{\text {Free }}$ and $\mathrm{vOH}_{\pi}$ bands: At all studied temperatures the maximum absorbance at $\sim 3530 \mathrm{~cm}^{-1}\left(\mathrm{vOH}_{\pi}\right)$ is higher than the absorbance at $\sim 3570 \mathrm{~cm}^{-1}\left(\mathrm{vOH}_{\text {Free }}\right)$ for 2nTADDOL, while we find the opposite trend for 1nTADDOL. Thus, much more free $\mathrm{OH}$ groups are

a Note that we thus neglect the dissociation of intramolecular bonds to from free-OH and/or $\mathrm{OH} \cdots \pi$ bonds, which can be justified by the fact that $\mathrm{vOH}_{\text {intra }}$ is red-shifted by more than $150 \mathrm{~cm}^{-1}$ with respect $\nu \mathrm{OH}_{\pi}$, indicating a significantly lower energy barrier for dissociation of an $\mathrm{OH} \cdots \pi$ bond than for an intramolecular hydrogen-bonds. 
present in solutions of $1 \mathrm{nTADDOL}$ compared to $2 \mathrm{nTADDOL}$ at a given temperature, which could potentially explain the higher catalytic activity of $1 \mathrm{nTADDOL}$. However, similar to $\mathrm{OH} \cdots \pi$ bonds to toluene, we find also for a binding to benzaldehyde - a common substrate in TADDOL catalysis indications for more OH-benzaldehyde hydrogen-bonds formed for 2nTADDOL as compared to 1nTADDOL (see Fig. S10, SI) ${ }^{[5,9]}$ Hence, as the "bad catalyst" forms more intermolecular bonds with both toluene and benzaldehyde, the high catalytic activity of 1nTADDOL cannot solely be explained by considering intermolecular bonding.

The high catalytic activity of 1nTADDOL can be understood based on the binding entropy and binding kinetics. Both NMR and IR results show that the formation/dissociation kinetics of the $\mathrm{OH} \cdots \pi$ bonds are much slower for $1 \mathrm{nTADDOL}$ as compared to 2nTADDOL. This implies that the energetic barrier for toluene to dissociate from an $\mathrm{OH} \cdots \pi$ is higher for $1 \mathrm{nTADDOL}$ than for $2 \mathrm{nTADDOL}$. As typical reactants in TADDOL catalysis contain hydrogen-bond accepting groups, similar to toluene or benzaldehyde, such energetic barriers are very likely also relevant to TADDOL-substrate interactions in TADDOL catalysis, which will be subject to future studies. A higher energetic barrier for the dissociation of 1nTADDOL from its complex with e.g. benzaldehyde or toluene, leads to longer lifetimes of the reactive intermediate. Thus, our results point towards the binding kinetics being the molecular level-origin of the enhanced catalytic conversion of 1nTADDOL, rather than the previously proposed increased acidity. ${ }^{[7]}$

Further, given the similar $\mathrm{OH} \cdots \pi$ bond dissociation enthalpy, the reduced number of $\mathrm{OH} \cdots \pi$ bonds observed for 1nTADDOL, relative to 2nTADDOL, can only have entropic origins. Such entropically reduced intermolecular interaction result from a reduced number of $\mathrm{OH} \cdots \pi$ bonded conformations for the more rigid $1 \mathrm{nTADDOL}$ compared to $2 \mathrm{nTADDOL}$. The conformationally constrained $1 \mathrm{nTADDOL}$ can thus provide a better-defined intermolecular bonding geometry with toluene, and such rigid bonding geometry is almost certainly related to the high stereoselectivity of 1nTADDOL.

\section{Concluding Remarks}

We report an IR and NMR study on hydrogen-bonding of the organo-catalysts 1nTADDOL and 2 nTADDOL. For the efficient asymmetric organo-catalyst $1 \mathrm{nTADDOL}$, three distinct $\mathrm{OH}$ bonding motifs can be resolved from both the IR and the NMR spectra: an intramolecularly hydrogen-bonded $\mathrm{OH}$ group, an $\mathrm{OH}$ group forming an intermolecular $\mathrm{OH} \cdots \pi$ bond to the solvent, and free $\mathrm{OH}$ groups that are not engaged in either intra- or inter-molecular interactions. These bonding motifs are only found in aromatic solvents benzene and toluene, while the free and intermolecular $\mathrm{OH}$ bonds cannot be resolved in other solvents. While similar bonding motifs are present in the IR spectra of the relatively inefficient catalyst 2nTADDOL, the two OH groups of 2nTADDOL give rise to a single, motionally averaged proton peak in the NMR spectra. Thus, both the intermolecular and intramolecular hydrogenbonds of 1nTADDOL exchange extremely slow in toluene, while the hydrogen-bond dynamics in 2nTADDOL are markedly faster. Remarkably, as judged from the infrared band intensity of the free $\mathrm{OH}$ group, the efficient catalyst 1nTADDOL forms less intermolecular bonds than the poor catalyst 2nTADDOL, which we ascribe to the bonding entropy. Our results thus suggest that the entropically reduced intermolecular interaction of 1nTADDOL is related to the high stereoselectivity in catalysis, while and the slow binding kinetics give rise to 1nTADDOL's efficient catalytic conversion.

\section{Experimental section}

Materials $1 \mathrm{nTADDOL} \quad\left((4 S\right.$-trans $)$-2,2-Dimethyl- $\alpha, \alpha, \alpha^{\prime}, \alpha^{\prime}$-tetra(1-naphthyl)-1,3-dioxolane-4,5-

dimethanol, SigmaAldrich, $99 \%)$ and 2nTADDOL ((4S-trans)-2,2-Dimethyl- $\alpha, \alpha, \alpha^{\prime}, \alpha^{\prime}$-tetra(2naphthyl)-1,3-dioxolane-4,5-dimethanol, SigmaAldrich, $98 \%)$ were used without further purification. 
All samples were prepared by weight on an analytical balance and the solvent was added using a syringe. Unless otherwise stated we used concentrations of $30 \mathrm{mM}$ TADDOL for ${ }^{1} \mathrm{H}$ NMR experiments, of $\sim 100 \mathrm{mM}$ for solvent dependent IR experiments ( $\sim 50 \mathrm{mM}$ for $\mathrm{CHCl}_{3}$ due to the limited solubility), and $\sim 150 \mathrm{mM}$ for temperature dependent IR experiment. We estimate the water content of TADDOL solutions to $\sim 70 \mathrm{ppm}$, as determined by ${ }^{1} \mathrm{H}$ NMR spectrum of 2 nTADDOL in toluene- $\mathrm{d}_{8}$. For the preparation of 1nTADDOL- $\mathrm{d}_{2}, 1 \mathrm{nTADDOL}$ was dissolved in toluene- $\mathrm{d}_{8}$ (SigmaAldrich, 99.6 atom \%D, $<100$ ppm water impurity) together with $\mathrm{D}_{2} \mathrm{O}$ (SigmaAldrich, 99.9 atom \%D) at a 1:30 molar ratio. The mixture was stored for $\sim 24$ hours and dried using Molecular Sieve (SigmaAldrich, $3 \AA$ ).

NMR spectroscopy ${ }^{1} \mathrm{H}$ NMR spectra were recorded using a $850 \mathrm{MHz}$ NMR spectrometer (Brucker, Avance III). The spectra were recorded with a $\pi / 2$-pulse length of $14.7 \mathrm{~ms}(12 \mathrm{scans}$, spectral width $17000 \mathrm{~Hz}$ ) and a relaxation delay of $2 \mathrm{~s}$. Spectra were referenced to the chemical shifts of residual toluene peaks $\left(\mathrm{C}_{6} \mathrm{D}_{5} \mathrm{CD}_{2} \mathrm{H}\right) .{ }^{1} \mathrm{H}$-DOSY spectra were recorded using a $5 \mathrm{~mm}$ TXI $1 \mathrm{H} / 13 \mathrm{C} / 15 \mathrm{~N}$ z-gradient probe with a gradient strength of $5.350\left[\mathrm{G} \mathrm{mm}^{-1} 1\right]$. The gradient was varied using 32 steps from $2 \%$ to $100 \%$ and the diffusion time was set to $40 \mathrm{~ms}$. The temperature of NMR measurements controlled to an accuracy of +/- $0.1 \mathrm{~K}$ and calibrated with a standard ${ }^{1} \mathrm{H}$ methanol NMR sample using the Topspin 3.1 software (Bruker). For temperature dependent experiments, we used a variable temperature unit.

Infrared spectroscopy FTIR spectra were recorded with $4 \mathrm{~cm}^{-1}$ spectral resolution using a Brucker, Vertex 70 FTIR spectrometer. The sample was kept between two $\mathrm{CaF}_{2}$ windows separated by a $200 \mu \mathrm{m}$ PTFE spacer. To isolate the spectra of TADDOL, we subtract the absorption of the windows and of the solvent at ambient temperature from the measured infrared absorption spectra. For temperature dependent experiments, the sample is mounted in cell, which is heated by four heating carriages and the temperature is monitored and actively controlled using a thermocouple.

\section{Acknowledgements}

We thank Mischa Bonn for fruitful discussion. B.M. gratefully acknowledges financial support from Alexander von Humboldt foundation. This project has received funding from the European Research Council (ERC) under the European Union's Horizon 2020 research and innovation program (grant agreement no. 714691).

\section{Conflict of interest}

The authors declare no conflict of interest.

\section{Keywords}

Organocatalysis - IR spectroscopy - NMR spectroscopy - Hydrogen-bonding

\section{References}

[1] T. P. Yoon, E. N. Jacobsen, Science 2003, 299, 1691-1693.

[2] D. W. C. MacMillan, Nature 2008, 455, 304-308.

[3] A. Dondoni, A. Massi, Angew. Chemie - Int. Ed. 2008, 47, 4638-4660.

[4] A. G. Doyle, E. N. Jacobsen, Chem. Rev. 2007, 107, 5713-5743.

[5] M. S. Taylor, E. N. Jacobsen, Angew. Chemie - Int. Ed. 2006, 45, 1520-1543.

[6] Y. Huang, A. K. Unni, A. N. Thadani, V. H. Rawal, Nature 2003, 424, 146-146.

[7] A. N. Thadani, A. R. Stankovic, V. H. Rawal, Proc. Natl. Acad. Sci. U. S. A. 2004, 101, 58465850.

[8] X. Zhang, H. Du, Z. Wang, Y. D. Wu, K. Ding, J. Org. Chem. 2006, 71, 2862-2869. 
[9] H. Du, D. Zhao, K. Ding, Chem. - A Eur. J. 2004, 10, 5964-5970.

[10] Y. N. Belokon, S. Harutyunyan, E. V Vorontsov, D. Pripadchev, A. S. Sagyan, A. K. Beck, D. Seebach, Arkivoc 2004, 2004, 132-150.

[11] J. D. McGilvra, A. K. Unni, K. Modi, V. H. Rawal, Angew. Chemie - Int. Ed. 2006, 45, 6130 6133.

[12] A. S. Saghyan, P. Langer, Asymmetric Synthesis of Non-Proteinogenic Amino Acids, Wiley$\mathrm{VCH}, 2016$.

[13] X. Zhang, H. Du, Z. Wang, Y. Wu, K. Ding, J. Org. Chem. 2006, 71, 2862-2869.

[14] C. D. Anderson, T. Dudding, R. Gordillo, K. N. Houk, Org. Lett. 2008, 10, 2749-22752.

[15] R. Gordillo, T. Dudding, C. D. Anderson, K. N. Houk, Org. Lett. 2007, 9, 501-503.

[16] D. Seebach, A. K. Beck, A. Heckel, Angew. Chem. Int. Ed. 2001, 40, 92-138.

[17] D. P. Seebach D. A.; Beck, A K.; Wang, Y. M.; Hunziker, D.; Petter, W., Helv. Chim. Acta 1992, 75, 2171-2208.

[18] P. E. Hansen, J. Spanget-Larsen, Molecules 2017, 22, 552.

[19] J. S. Lomas, J. Phys. Org. Chem. 2011, 24, 129-139.

[20] J. S. Lomas, C. Cordier, J. Phys. Org. Chem. 2009, 22, 289-297.

[21] P. E. Hansen, J. Spanget-Larsen, J. Mol. Struct. 2012, 1018, 8-13.

[22] J. Spanget-Larsen, B. K. V. Hansen, P. E. Hansen, Chem. Phys. 2011, 389, 107-115.

[23] A. D. Bain, Prog. Nucl. Magn. Reson. Spectrosc. 2003, 43, 63-103.

[24] A. Allerhand, H. S. Gutowsky, J. Chem. Phys. 1964, 41, 2115-2126.

[25] P. Asselin, B. Madebène, P. Soulard, R. Georges, M. Goubet, T. R. Huet, O. Pirali, A. Zehnacker-Rentien, J. Chem. Phys. 2016, 145, 224313.

[26] E. Arunan, D. Mani, Faraday Discuss. 2015, 177, 51-64.

[27] M. A. Varfolomeev, D. I. Abaidullina, A. Z. Gainutdinova, B. N. Solomonov, Spectrochim. Acta - Part A Mol. Biomol. Spectrosc. 2010, 77, 965-972.

[28] G. Litwinienko, G. A. Di Labio, P. Mulder, H.-G. Korth, K. U. Ingold, J. Phys. Chem. A 2009, $113,6275-6288$.

[29] H. Kleeberg, D. Klein, W. A. P. Luck, J. Phys. Chem. 1987, 91, 3200-3203.

[30] M. Olschewski, S. Knop, J. Lindner, P. Vöhringer, Angew. Chemie - Int. Ed. 2013, 52, 9634 9654.

[31] D. R. Lide, CRC Handbook of Chemistry and Physics 87th Edition, Taylor And Francis Group, 2006.

[32] M. C. Foti, L. R. C. Barclay, K. U. Ingold, J. Am. Chem. Soc. 2002, 124, 12881-12888.

[33] M. H. Abraham, P. L. Grellier, D. V. Prior, J. J. Morris, P. J. Taylor, J. Chem. Soc., Perkin Trans. 2 1990, 521-529.

[34] J. Zheng, K. Kwak, X. Chen, J. B. Asbury, M. D. Fayer, J. Am. Chem. Soc. 2006, 128, $2977-$ 2987.

[35] J. Zheng, K. Kwak, J. Asbury, X. Chen, I. R. Piletic, M. D. Fayer, Science 2005, 309, 1338 1342.

[36] J. J. Loparo, S. T. Roberts, R. A. Nicodemus, A. Tokmakoff, Chem. Phys. 2007, 341, 218 229.

[37] J. J. Loparo, S. T. Roberts, R. A. Nicodemus, A. Tokmakoff, Chem. Phys. 2009, 361, 185.

[38] J. Zheng, M. D. Fayer, J. Am. Chem. Soc. 2007, 129, 4328-4335.

[39] D. Ojha, K. Karhan, T. D. Kühne, Sci. Rep. 2018, 8, 1-8.

[40] B. Cohen, S. Weiss, J. Chem. Phys. 1980, 72, 6804.

[41] R. E. Weston, J. Chem. Phys. 1981, 74, 3634-3635. 


\section{Graphical Abstract}

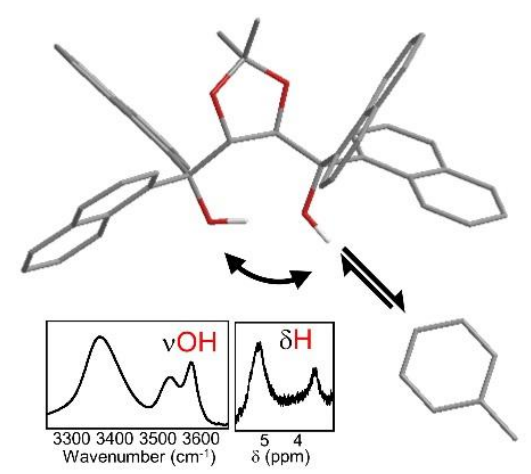

The less the merrier: Spectroscopic comparison of hydrogen-bonding dynamics of two isomeric diolbased organo-catalysts shows that the good catalyst forms less intermolecular bonds than the poor catalyst. Our results suggest, that - rather than the strength of the intermolecular hydrogen bond bonding kinetics and bonding entropy determine the catalytic efficiency. 